Volume 16, Number 4-April 2010

Conference Summary

\title{
Findings, Gaps, and Future Direction for Research in Nonpharmaceutical Interventions for Pandemic Influenza
}

Charles J . Vukotich, J r., $\square$ Rebecca M. Coulborn, Tomas J . Aragon, Michael G. Baker, Barri B. Burrus, Allison E. Aiello, Benjamin J . Cowling, Alasdair Duncan, Wayne

Enanoria, M. Patricia Fabian, Yu-hui Ferng, Elaine L. Larson, Gabriel M. Leung, Howard Markel, Donald K. Milton, Arnold S. Monto, Stephen S. Morse, J . Alexander Navarro,

Sarah Y. Park, Patricia Priest, Samuel Stebbins, Alexandra M. Stern, Monica Uddin, and Scott F. Wetterhall

Author affiliations: University of Pittsburgh, Pennsylvania, USA (C.J. Vukotich, S. Stebbins); University of Michigan, Ann Arbor, Michigan, USA (R.M. Coulborn, A.E. Aiello, H. Markel, A.S. Monto, J.A. Navarro, A.M. Stern, M. Uddin); University of California, Berkeley, California, USA (T.J. Aragon, W. Enanoria); University of Otago, Dunedin, New Zealand (M.G. Baker, A. Duncan, P. Priest); RTI International, Research Triangle Park, North Carolina, USA (B.B. Burrus, S.F. Wetterhall); University of Hong Kong, Hong Kong, People's Republic of China (B.J. Cowling, G. M. Leung); University of Massachusetts, Lowell, Massachusetts, USA (M.P. Fabian); Columbia University, New York, New York, USA (Y. Ferng, E.L. Larson, S.S. Morse); University of Maryland, College Park, Maryland, USA (D.K. Milton); and Hawaii Department of Health, Honolulu, Hawaii (S.Y. Park)

\section{Suggested citation for this article}

In June 2006, the Centers for Disease Control and Prevention (CDC) released a request for applications to identify, improve, and evaluate the effectiveness of nonpharmaceutical interventions (NPIs) to mitigate the spread of pandemic influenza within communities and across international borders (RFA-CI06-010) (1). Eleven studies (Table 1) were funded to identify optimal, discrete, or combined NPIs for implementation during an influenza pandemic. During March 4-6, 2009, the principal investigators met to share results, identify research gaps, and define future research needs in 9 areas as described here. A total of 16 research gaps were identified (Table 2).

NPI behaviors can be successfully taught to and adopted by a variety of persons through community health education, interactive classroom teaching, or Internet-based instruction (모.). Urban Hispanics had misunderstandings about influenza (e.g., 88\% thought that influenza was caused by bacteria). Their knowledge, attitudes, and practices improved through a community education program (4). Acceptability of NPIs also depends on early planning, consistent and targeted communication during implementation, and clear delineation of responsibilities and authority. Acceptability further requires communication from traditional (i.e., emergency response organizations) and nontraditional (i.e., churches) sources.

Behaviors perceived as typical daily behavior were more readily accepted than nontypical daily behaviors Hand sanitizing with alcohol-based preparations, washing with soap, covering sneezes and coughs, and 
being aware of one's hands (e.g., touching face) showed relatively high compliance. Only 1 of 5 projects had good adherence to face mask use, which is not a typical behavior (2).

In addition, efficacy of face masks for preventing transmission of influenza viruses has yet to be fully determined. Influenza virus nucleic acid was present in fine-particle aerosols from influenza patients in tidal breathing (14\%-33\%) and coughing (64\%) (ㅁ). Preliminary results demonstrate that surgical ear-loop face masks limit the generation of droplets ( $\geq 5.0 \mu \mathrm{m}$ in diameter) containing influenza virus RNA.

NPIs can be efficacious for reducing rates of influenza and influenza-like illness (ILI) in community settings. Household secondary attack ratios were substantially reduced (adjusted odds ratio $0.33,95 \% \mathrm{Cl} 0.13-0.87$ ) if all household members practiced frequent hand washing and wore face masks within 36 hours after symptom onset in the index patient (ㅁ). University students had a 50\%-65\% reduced rate of ILI over a 6 week intervention period, using hand hygiene and masks ( $(\underline{7})$. Mask use was substantial (4-5 hours per day average), which was attributed to adoption of masks as a daily behavior, rather than as a response to illness. Elementary school students using a 5-layered NPI approach, including hand hygiene and cough etiquette, had 53\% fewer laboratory-confirmed influenza A infections and 26\% fewer total absences compared with a control group.

Household crowding (measured as a deficit of $\geq 2$ bedrooms) can be a factor in community influenza transmission, significantly increasing the relative risk (RR) for hospitalization for pneumonia or influenza (RR $=1.20,95 \% \mathrm{Cl} 1.05-1.37$; age standardized). The mean serial interval (i.e., the time between successive cases of infectious diseases in the chain of transmission) was 3.6 days, based on pairs of persons in 14 households (ㅇ).

School dismissal is part of CDC's pandemic planning, but dismissed students may congregate elsewhere. The number of social contacts by children dropped $67 \%(p<0.05)$ during school holidays, suggesting that recongregation may not be a factor in school closure and that school dismissal might increase social distancing during pandemic influenza.

Three studies assessed the use of Quidel QuickVue Influenza A+B Rapid Test in the community and found a median sensitivity of $27 \%$, despite manufacturer reports of $73 \%$. No cause for this sensitivity has been shown (9).

Rapid, large-scale risk-based entry screening of air travelers for ILI that used questionnaires and health assessments was conducted successfully at 2 airports for 177 flights. Seventy-five percent of passengers who provided contact details were followed up, but few of those with symptoms were prepared to go to a laboratory for collection of a respiratory specimen. On the basis of preliminary analysis, investigators concluded that voluntary travel restrictions would sufficiently protect only isolated populations with low numbers of visitors $(\underline{10})$.

Investigators have collected newspapers, official health reports at all levels, scholarly literature, and archived material from governments and agencies. This material is being compiled into The American Influenza Epidemic of 1918-1919: A Digital Encyclopedia, an archive of historical material $(\underline{11}, 12)$.

Meeting participants concluded that evidence exists of the effectiveness of NPIs, including face masks, hand hygiene, cough etiquette, reduced crowding, and school closures, in reducing the spread of influenza. Insufficient sample sizes, exacerbated by a mild influenza season during the first funding year, underreporting of disease, and challenges faced by influenza surveillance limited the statistical power of most studies. Further studies with larger sample sizes, common methods to allow pooling of data, and study durations that cover multiple influenza seasons are needed to address these limitations. In addition, studies using 
engineering controls, such as upper-room ultraviolet $C$ lighting, in populations with naturally acquired infection are needed to address the relative contribution of transmission modalities, e.g., small vs. large respiratory droplets and contact transmission.

\section{Acknowledgments}

We thank all the meeting participants for their thoughtful presentations and discussions. We also thank Leslie Fink for editing of and review of the manuscript.

This research was supported by the Centers for Disease Control and Prevention under a series of cooperative agreements named herein, emanating from RFA-CI06-010, issued on June 16, 2006.

\section{References}

1. Morse SS, Garwin RL, Olsiewski PJ. Public health. Next flu pandemic: what to do until the vaccine arrives? Science. 2006;314:929. PubMed DOI

2. Stebbins S, Downs JS, Vukotich CJ Jr. Using nonpharmaceutical interventions to prevent influenza transmission in elementary school children: parent and teacher perspectives. J Public Health Manag Pract. 2009;15:112-7.

3. Samuel S, Stark JH, Vukotich CJ Jr. Compliance with a multilayered non-pharmaceutical intervention in an urban elementary school setting. J Public Health Manag Pract. In press.

4. Larson E, Ferng YH, Wong J, Alvarez-Cid M, Barrett A, Gonzalez MJ, et al. Knowledge and misconceptions regarding upper respiratory infections and influenza among urban Hispanic households: need for targeted messaging. J Immigr Minor Health. 2009;11:71-82. PubMed DOI

5. Fabian P, McDevitt JJ, DeHaan WH, Fung RO, Cowling BJ, Chan KH, et al. Influenza virus in human exhaled breath: an observational study. PLoS One. 2008;3:e2691. PubMed DOI

6. Cowling BJ, Chan KH, Fang VJ, Cheng CKY, Fung ROP, Wai W, et al. Facemasks and hand hygiene to prevent influenza transmssion in households: a randomized trial. Ann Intern Med. 2009;151:43746.

7. Aiello AE, Murray G, Coulborn R, Noone A, Monto AS. Mask use reduces seasonal influenza-like illness in the community setting. 46th Annual Meeting of the Infectious Diseases Society of America Published Abstract; 2008 October 25-28, Washington, DC; 2008.

8. Cowling BJ, Fang VJ, Riley S, Malik Peiris JS, Leung GM. Estimation of the serial interval of influenza. Epidemiology. 2009;20:344-7. PubMed DOI

9. Uyeki TM, Prasad R, Vukotich C, Stebbins S, Rinaldo CR, Ferng YH, et al. Low sensitivity of rapid diagnostic test for influenza. Clin Infect Dis. 2009;48:e89-92. PubMed DOI

10. Nishiura $\mathrm{H}$, Wilson N, Baker MG. Quarantine for pandemic influenza control at the borders of small island nations. BMC Infect Dis. 2009;9:27. PubMed DOI

11. Stern AM, Cetron MS, Markel H. Closing the schools: lessons from the 1918-19 U.S. influenza pandemic. Health Aff (Millwood). 2009;28:w1066-78.

12. Markel H, Stern AM, Cetron MS. Non-pharmaceutical interventions employed by major American cities during the 1918-19 influenza pandemic [discussion 138-42]. Trans Am Clin Climatol Assoc. 2008;119:129-38.

\section{Tables}


Findings, Gaps, and Future Direction for Research in Nonpharmaceutical Interventions for Pandemic Influenza | CDC EID

Nonpharmaceutical Intervention Studies for Pandemic Influenza RFA-Cl06-010

Table 2. Research gaps in identifying, improving, and evaluating the effectiveness of NPIs in mitigating the spread of pandemic influenza

\section{Suggested Citation for this Article}

Vukotich CJ Jr, Coulborn RM, Aragon TJ, Baker MG, Burrus BB, Aiello AE, et al. Findings, gaps, and future direction for research in nonpharmaceutical interventions for pandemic influenza [conference summary].

Emerg Infect Dis [serial on the Internet]. 2010 April [date cited]. www.cdc.gov/EID/content/16/4/e2.htm

DOI: 10.3201/eid1604.090719 